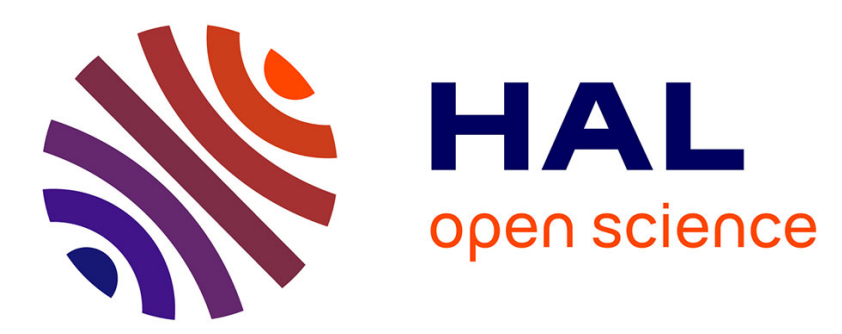

\title{
Micellar electrokinetic chromatography for the determination of cortisol in urine samples in view of biomedical studies
}

Ilona Olędzka

\section{- To cite this version:}

Ilona Olędzka. Micellar electrokinetic chromatography for the determination of cortisol in urine samples in view of biomedical studies. Electrophoresis, 2010, 31 (14), pp.2356. 10.1002/elps.201000144 . hal-00599464

\section{HAL Id: hal-00599464 \\ https://hal.science/hal-00599464}

Submitted on 10 Jun 2011

HAL is a multi-disciplinary open access archive for the deposit and dissemination of scientific research documents, whether they are published or not. The documents may come from teaching and research institutions in France or abroad, or from public or private research centers.
L'archive ouverte pluridisciplinaire HAL, est destinée au dépôt et à la diffusion de documents scientifiques de niveau recherche, publiés ou non, émanant des établissements d'enseignement et de recherche français ou étrangers, des laboratoires publics ou privés. 


\section{ELECTROPHORESIS}

Micellar electrokinetic chromatography for the determination of cortisol in urine samples in view of biomedical studies

\begin{tabular}{|r|l|}
\hline Journal: & Electrophoresis \\
\hline Manuscript ID: & elps.201000144.R1 \\
\hline Wiley - Manuscript type: & Short Communication \\
\hline Date Submitted by the \\
Author: & $30-$ Apr-2010 \\
\hline Complete List of Authors: & Olędzka, Ilona; Medical University, Pharmaceutical Chemistry \\
\hline Keywords: & $\begin{array}{l}\text { cortisol, micellar-electrokinetic capillary chromatography, biomarker } \\
\text { of stress }\end{array}$ \\
\hline &
\end{tabular}

\section{S ScholaroNe \\ Manuscript Central}


Micellar electrokinetic chromatography for the determination of cortisol in urine samples in view of biomedical studies

Ilona Olędzka*, Alina Plenis, Lucyna Konieczna, Piotr Kowalski, Tomasz Bączek

Department of Pharmaceutical Chemistry, Medical University of Gdańsk, Hallera 107, 80416, Gdańsk, Poland

* Corresponding author: Tel.: +48 58 3493136; Fax: +48 58 3493130;

e-mail: ilona@gumed.edu.pl

Keywords: cortisol, micellar-electrokinetic capillary chromatography, biomarker of stress 


\begin{abstract}
Micellar electrokinetic capillary chromatographic (MEKC) method used for determination of cortisol in urine was developed and elaborated. In turn, the measurements of urinary free cortisol provided the diagnostic information for excess adrenal production of cortisol. MEKC realized by the addition of anionic surfactant sodium dodecyl sulfate (SDS) to the buffer solution, was demonstrated as to be the appropriate mode for the separation of cortisol and dexamethasone used as internal standard. A buffer solution composed of $10 \mathrm{mM}$ sodium tetraborate and $50 \mathrm{mM}$ SDS at $\mathrm{pH} 8.8$ was used. The MEKC assay was evaluated by analyzing a series of urine samples containing cortisol in variable concentrations. The proposed method was validated for specificity, linearity, limits of detection and quantitation, precision and trueness. The quantitation limit for cortisol equaled $5 \mathrm{ng} / \mathrm{ml}$. The method was selective, and reliable for identity and enable to detect changes of endogenous levels of cortisol in urine under different stress situations.
\end{abstract}




\section{Introduction}

Cortisol is the major glucocorticoid produced by the adrenal glands in humans. It regulates a myriad of biological function and has anti-inflammatory and immunosuppressive effects. Moreover, it was found that it is also a biological biomarker of stress, anxiety and depression. Urinary free cortisol (UFC) reflects the fraction of nonprotein bound plasma cortisol. It is commonly and perhaps uncritically assumed that only free cortisol is the biologically active fraction. Furthermore, measurements of UFC is important in the diagnosis and management of adrenal disorders [1].

Several methods for the determination of cortisol in various types of biological samples (plasma, serum, urine, saliva) have been described in recent years, unfortunately all of them possess also several limitations [2-11]. The measuring cortisol in saliva has many advantages including the easy of sampling. It is stress-free, non-invasive, and allows for frequent and rapid sampling $[2,4,8,10]$. However, salivary cortisol levels are only 50-70\% of serum free cortisol levels due to the conversion of cortisol to cortisone by $11 \beta$ hydroxysteroid dehydrogenase type 2 activity in saliva [7]. On the other hand, the sampling of blood may itself induce stress, and the sample represents a cumulative response [7, 11]. Kartsova et al. [9] studied the MEKC with UV detection for determining corticosteroids in biological fluids such as, blood, serum and urine, with the use of various versions of online preconcentration. However, the method employed a labor intensive manual liquid/liquid extraction procedure with methylene chloride (chloroform). Despite the successful use of halogenated solvents, such as dichloromethane and chloroform, this solvents should be avoided when new methods are developed, since these solvents are banned from use in a number of countries because of their negative effects on the environment. 
In clinical laboratories, steroid hormones in urine are usually analyzed by immunological techniques [8, 10], high-performance liquid chromatography [3, 6, 12-14], gas chromatography (GC) [15], liquid chromatography (LC) [16-19], liquid chromatographytandem mass spectrometry (LC-MS/MS) [20], thin-layer chromatography (TLC) [21] and capillary electrophoresis (CE) [9, 22-25]. The immunoassay methods are rapid and simple, but the authors of a large number of publication point to the fact that most immunoassay applications for urinary free cortisol do not measure cortisol alone, but also the interfering material with apparently cortisol metabolites or adrenally derived cortisol prevailing. Although the HPLC method does not suffer from cross-reactivity between the different corticosteroids, the resolution of the method is low and rather large volumes of eluents are required. The application of MEKC to urine samples is potentially difficult due to the low sensitivity for absorbance detection, clogging of capillaries and current errors. However, through pretreatment of samples the concentrations of the analytes can be increased sufficiently for clinical applications. Since its introduction in 1984 by Terabe et al. [26], micellar electrokinetic chromatography has gained wide popularity. It has been used for the separation of various hydrophobic compounds such as steroids. In MEKC anionic or cationic surfactants were added at a higher concentration than the critical micelle concentration (CMC) to the electrolyte solution, forming a pseudo-stationary micellar phase. The migration order for neutral analytes is related to the hydrophobicity of the analyte: more hydrophobic analytes migrate slower than less hydrophobic ones. The migration time of the neutral analyte is limited between the migration time of electroosmotic flow (EOF) and of the micelle. Steroids, which are electrically neutral and high lipophilic drugs, can be separated by using MEKC mode [25-30]. Nishi et al. [27] were the first to demonstrate the applicability of MEKC for separating various corticosteroids on a fused-silica capillary using a sodium dodecyl sulfate (SDS)-bile salts mixed micelle system. Addition of the organic modifiers such 
as bile salts to SDS was found to be essential in achieving separation of steroids in a mixture because its influence of resolution. Valbuena et al. [25] were developed anionic-zwitterionic mixed micelles in micellar electrokinetic separation of clinically relevant steroids in serum and urine on a fused-silica capillary. A SDS/SB3-12 (sodium dodecyl sulphate/ N-dodecylN,N-dimethyl-3-ammonio-1-propanesulfonate) mixed micellar system allows to achieve baseline separation of eight steroids in less than $10 \mathrm{~min}$ and the detection limit of $1-5 \mu \mathrm{g} / \mathrm{ml}$. Abubaker et al. [23] were separated of six structurally similar, hydrophobic steroids by MEKC with dodecyltrimethylammonium bromide (DTAB) as cationic surfactant. They achieved a detection limit of $500 \mathrm{ng} / \mathrm{ml}$ for each steroid in urine samples. Noé et al. [30] evaluated and optimized the separation buffers for the determination of corticosteroids with MEKC. Baseline separation at long migration times was achieved with a phosphatetetraborate buffer $(\mathrm{pH} 9.0,50 \mathrm{mM})$ containing $50 \mathrm{mM}$ each of SDS, dehydrocholic acid sodium salt and glycodeoxycholic acid sodium salt. Bile salts can be used as micelle forming agent solely or in combination with other micelle forming substances. The analysis time was $40 \mathrm{~min}$ and limit of detection was $20 \mu \mathrm{g} / \mathrm{ml}$. Kartsova et al. [9] were compared characteristic of HPLC and MEKC in determining of corticosteroids. The results shown, that the detection limit in HPLC without preconcentration is lower than in MEKC, and equaled $20 \mu \mathrm{g} / \mathrm{l}$ and 50 $\mu \mathrm{g} / \mathrm{l}$, respectively. But with preconcentration procedure the detection limit was similar in both methods, 2 and $3 \mu \mathrm{g} / 1$, respectively. The analysis time is shorter in MEKC (15 min) compared with HPLC (34 min). In turn, Rao et al. [22] developed MEKC with SDS and solid-phase extraction for determination of a urinary free cortisol. The extraction was accomplished in 1015 min with a recovery of $89-94 \%$. According to the authors, cortisol at these physiological levels can be easily detected by subjecting a $15 \mathrm{ml}$ of urine sample. The detection limit of free cortisol in urine, as described the authors, was $10 \mu \mathrm{g} / \mathrm{l}$ with SPE compared to $500 \mu \mathrm{g} / \mathrm{l}$ without SPE. 
To summarize a portion of the research on steroid hormone MEKC analysis published during the last decade, our opinion is that, although many systematic investigations have been carried out to establish new analytical methods for these compounds in complex biological matrices, there are still problems in analyzing at the trace levels.

In the present study, a solid-phase extraction (SPE) coupled MEKC with UV detection as a potential analytical method for the separation of urinary free cortisol was elaborated. The main advantages of MEKC are high efficiency, speed, solvent saving and minimal sample requirement (sample size 10-30 $\mathrm{nl}$ injected). Our work proposes an easy and rapid method using MEKC with UV detector to determine cortisol in human urine. The UV detector has been the most popular and useful, whereas mass spectrometry (MS) has been less frequently applied in common laboratories due to the high instrumentation cost. Since most commercial CE instruments are equipped with UV-Vis detectors, many applications have been published using absorbance detection. Researchers applying UV detection have mostly used the method of pre-concentration of following large volume of urine, namely $2 \mathrm{ml}$ [9], $10 \mathrm{ml}$ [24] and 15 $\mathrm{ml}$ [22]. For that reason we decided to develop $15 \mathrm{ml}$ volume sample. This manner allowed to us to determine this hormone in real samples, because the concentration of free steroids in biological fluids are at the level of ng/ml. Due to steroids are non-volatile and unstable in high temperature the GC is rarely used in clinical practice. In turn, thanks to steroids have UV absorption at $254 \mathrm{~nm}$, they should be easily detect with UV detectors. Due to the path length sensitivity of absorbance measurements, several attempts have been made to improve detection limits. Moreover, to improve detection of cortisol, in our paper, preconcentration of urine samples has been employed. Validation aspects such as linearity, specificity, repeatability, precision, trueness and sensitivity were successfully assessed. Additionally, the application of MEKC method to screen for level of cortisol in human urine samples was also investigated in this study. 


\section{Materials and methods}

\subsection{Chemicals and reagents}

The buffer solution for CE analysis was prepared from sodium tetraborate decahydrate and sodium dodecyl sulfate (SDS) (Merck, Germany). Cortisol (11 $\beta, 17 \alpha, 21$-trihydroxypregn-

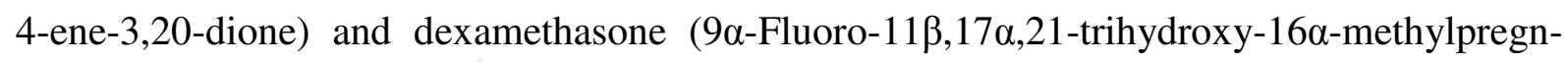
1,4-dien-3,20-dione) were purchased from Sigma (St. Louis, MO, USA) and were of a minimum purity of $99 \%$. Each of steroids was accurately weighed, dissolved in methanol and diluted to an appropriate concentration. All solutions of the analytes were stored at $4{ }^{\circ} \mathrm{C}$ until analysis to avoid decomposition.

Dichloromethane, acetone and methanol were obtained from Merck (Germany). Highly pure water was obtained from Milli-Q equipment (Millipore, Bedford, MA, USA).

\subsection{Apparatus}

Analysis was done using a Beckman P/ACE 2100 (Beckman Instruments, Fullerton, CA, USA) equipped with Gold software for data analysis, selectable fixed-wavelength UV detector and an autosampler. The capillary cartridge contained a $75 \mu \mathrm{m}$ i.d. unmodified silica capillary, $57 \mathrm{~cm}$ total length and $51 \mathrm{~cm}$ effective length to the detector. The voltage was maintained at $20 \mathrm{kV}$. Detection of steroids was performed at $254 \mathrm{~nm}$ (wavelength of absorption maximum). The background electrolyte for electrophoretic separation consisted of $50 \mathrm{mM}$ SDS and $10 \mathrm{mM}$ sodium tetraborate $(\mathrm{pH}=8.8)$. Analytes were introduced into the capillary at anode via a $5 \mathrm{~s}$, whereas the detector was set on the cathode end of the capillary. In order to equilibrate the capillary and minimize hysteresis effects, the capillary was 
regenerated between each run by treatment with $0.1 \mathrm{M}$ hydrochloric acid $(0.3 \mathrm{~min})$, next with methanol $(0.7 \mathrm{~min})$, then with regeneration solution $0.1 \mathrm{M}$ sodium hydroxide $(1 \mathrm{~min})$ and finally with triple distilled water $(1 \mathrm{~min})$. Each day before analysis the system was first purged with regeneration solution for $5 \mathrm{~min}$, followed triple distilled water for $10 \mathrm{~min}$ and the working buffer solution for next $10 \mathrm{~min}$.

\subsection{Sample preparation}

The urine was obtained from adult volunteers and frozen at $-20^{\circ} \mathrm{C}$. Before extraction samples were left to thaw and equilibrate to room temperature. Cortisol levels were standardized by correction for creatinine excretion, with results expressed as cortisol-tocreatinine ratio. The amount of cortisol in the urine reflects the average cortisol concentration in the blood at the time that the urine was formed. However, this measurement is affected by the concentration of the urine. Due to creatinine is a product of muscle metabolism and it is normally lost in the urine at a relatively steady rate, the ratio of cortisol to creatinine in the urine can be used to account for the effect of urine concentration. Simple stress may cause a mild increase in urinary cortisol/creatinine ratio. The presence of other illnesses may also result in increased cortisol production by the adrenal glands and thereby increase this ratio [8, 13, 16]. The level of creatinine in urine samples of subjects was studied, because the increased value indicate of renal failure and/or a reduced glomerular filtration. It may cause an increase (or decrease) the contents of designated substances in urine.

Creatinine in urine was investigated using a diagnostic kit for the determination of creatinine PZ CORMAY (Lublin, Poland). The colorimetric method based on reaction with picrinic acid, according to the methodology supplied, was used.

Urine samples $(15 \mathrm{ml})$ were spiked with $500 \mathrm{ng} / \mathrm{ml}$ dexamethasone (internal standard) and various concentrations $(5-400 \mathrm{ng} / \mathrm{ml})$ of cortisol. Preconcentration of cortisol from urine 


\section{Results and discussion}

The aim of this study was to develop a MEKC technique as an alternative method in routine analysis for determination of endogenous low-hydrophylic steroid hormone. To detect physiological levels of cortisol ranged $50-200 \mathrm{ng} / \mathrm{ml}$, preconcentration of urine samples is necessary. In developing the method for the determination of cortisol in the urine the study start by analyzing $1 \mathrm{ml}$ of urine and then 3,5 and $10 \mathrm{ml}$. However, in each case after the extraction of the urine achieved LOD and LOQ limits were not satisfactory. It was not possible to detect cortisol levels in the full range of physiological concentrations. Cortisol at these physiological levels can be easily detected by subjecting a $15 \mathrm{ml}$ of urine sample to the sample clean-up and preconcentration.

\subsection{Optimization of sample extraction}

Biological samples are often too complex to permit analysis by direct injection and require the removal of endogenous compounds. Extraction methods are attractive for two 
reasons [31]. They selectively collect the analyte of interest plus a part of the endogenous components, whereas the other endogenous components are removed. Secondly, the analyte can simultaneously be concentrated by one or two orders of magnitude. The main disadvantages of extraction techniques are the time and effort they require and the potential of losses of the analyte. In order to isolate the test compound from the urine extraction the following procedure were investigated: liquid-liquid extraction (LLE) and solid phase extraction (SPE). In LLE hydrophobic sample components (i.e., cortisol) are extracted with a water-immiscible organic phase [14]. The various organic solvents as eluting solvents were used in this study (such as, ethyl acetate and dichloromethane). After extraction, the solvents can be evaporated and the residue reconstituted in a suitable buffer. The use of large amounts of organic solvents in LLE is a disadvantages as far as environmental and health aspects are concerned. During the solid phase extraction the sample was passed over a disposable column with nonpolar filling LC-18 by which some of the analytes was retained. After preconditioning of the sorbent the sample was applied. The sorbent was then selectively washed to remove undesirable components without the loss of the analyte of interest. The analytes are then eluted using a minimum of solvent which can be evaporated and redissolved in a buffer. Moreover, the SPE, now the most widely used, has many advantages such as the possibility of isolation and concentration of volatile and non-volatile analytes, which has a positive effect on further analysis and allows the lower limit of detection and determination of test compounds. In addition, it allows the storage of test compounds adsorbed on the sorbent for a long time and eliminates the formation of emulsions that occur during the extraction LLE. An important advantage is the reduction in the use of organic solvents [22]. Additionally, SPE can be easily incorporated into automated analytical procedures, which can lead to greater trueness and precision, as well as greater laboratory productivity. As a result, SPE has gained popularity in analytical labs, whereas the use of LLE is waning. The results of 
extraction efficiency of cortisol after various organic solvents used as eluents were presented in Table 1.

The influence of extraction type on the extraction efficiency was tested on urine samples spiked to level 20, 100 and $400 \mathrm{ng} / \mathrm{ml}$ of analytes. Different sorbent and organic solvents were tested for clean-up of the sample extract. Precipitation of organic material and extraction of cortisol was achieved by adding methanol, dichloromethane and acetonitrile to urine samples. The research has been shown that, the best extraction procedure based on using methanol. Best overall recovery for the hormone was obtained on $\mathrm{C}_{18}$ sorbents. The extraction efficiency after using methanol and $\mathrm{C}_{18}$ sorbents equaled $103.4 \%$ for $20 \mathrm{ng} / \mathrm{ml}, 97.6 \%$ for 100 $\mathrm{ng} / \mathrm{ml}$ and $100.4 \%$ for $400 \mathrm{ng} / \mathrm{ml}$. LLE was initially evaluated but the extract were found to be too dirty for MECK. The important reasons for the assay SPE are the cleaner background and higher recovery of cortisol and internal standard than after LLE, therefore SPE was proposed for removing the matrix of the sample. Recoveries (mean $\pm \mathrm{SD}$ ) were also determined for the internal standard after SPE with methanol extraction procedure and being for concentration $500 \mathrm{ng} / \mathrm{ml} 86.9 \pm 7.9 \%$

\subsection{Optimization of running buffer}

The constitution of the running buffer solution, including buffer composition, concentration and $\mathrm{pH}$ value, was considered as an important factor in MEKC because of its influence on the separation. The most commonly used surfactant is sodium dodecyl sulfate (SDS) which is an anionic surfactant and is attracted by the anode. However, the EOF causes the micelles to migrate to the cathode, in a slower rate than the bulk of the buffer. The different velocities of the EOF and the micellar phase permit electrophoretic separations, and provide a way to resolve charged as well as neutral molecules. Neutral solutes partition between the micelles and the background electrolyte, and are separated solely on 
chromatographic basis, whereas for ionic solutes separation is based on chromatography and electrophoresis. The micelles can be considered as a moving pseudostationary phase. Selectivity in MEKC is dependent on the concentration of the micelle-forming agent, the buffer $\mathrm{pH}$ and the use of additives, including organic modifiers and salts. It is important that surfactants present in concentration below the CMC also affect the mobility of analytes due to complexation of the analyte with one or more surfactant molecules [23, 25, 30]. SDS was added into the running buffer in this study. The SDS micelles enhanced solubility of the analytes and offered good resolution. The influence of the SDS concentration in the optimized tetraborate buffer was further evaluated for the resolution of the cortisol and dexamethasone (I.S.). The concentration of the micelle forming agent (SDS) was tested from 10 to $50 \mathrm{mM}$. Raising the concentration of SDS in buffer resulted in a increase of migration times for compounds of interest. At a concentration of $50 \mathrm{mM}$ of SDS the peaks were separated to the baseline. The neutral components of the test sample such as steroids are separated because of different distribution coefficients between a polar aqueous buffer and nonpolar micelles.

Second important parameter for MEKC separation is the $\mathrm{pH}$ of the buffer system. We studied the separation of cortisol in both alkaline and acidic buffer under conditions of MEKC with the use of SDS as micelle forming agent. In theory, the separation of steroids, being neutral molecules, should be independent of $\mathrm{pH}$ [9]. However, at basic $\mathrm{pH}$ the increased EOF reduced migration times of steroids but gave better efficiencies for resolved steroids when compared to the ones obtained at $\mathrm{pH}$ below 7. In alkaline $\mathrm{pH}$ the elution order of steroids corresponds to increasing hydrophobocity of the analytes. On the contrary, it is inverted in an acidic medium more hydrophobic steroids are eluted sooner. Reduced EOF under acidic conditions allows partitioning for a longer time period, thereby resulting in baseline separation of steroids. The migration time reached a minimum at $\mathrm{pH} 8.8$ and then started to increase at more alkaline $\mathrm{pH}$. At $\mathrm{pH}$ greater than 10 significantly loss in resolution. 
The influence on migration time and separation efficiency of the organic modifier methanol (10-20\%) added to buffer solution was also investigated. Generally, addition of methanol to the buffer resulted in decrease of separation efficiency. The using of number of borate and phosphate buffers and various concentration of SDS was investigated and the results were presented in Table 2. The exemplary electropherograms showing the effect of $\mathrm{pH}$ value in buffer on electrophoretic times and shape of cortisol and dexamethasone are depicted in Figure 1.

Finally, the $10 \mathrm{mM}$ borate buffer with the addition of $50 \mathrm{mM}$ SDS $(\mathrm{pH}=8.8)$ was chosen as a running buffer for the subsequent experiments.

\subsection{Optimization of instrument parameters}

The effect of separation voltage on resolution was investigated at voltage range of 10$25 \mathrm{kV}$. As expected, increase of voltage shortened the migration time and sharpened the peak shape. On the other hand, higher voltage resulted in higher CE currents and Joule heating which led to baseline noise and falling separation efficiency. A voltage of $20 \mathrm{kV}$ was selected as a good compromise between resolution and migration time.

The UV absorption spectra of cortisol and dexamethasone were examined in order to optimize the detection wavelength. The research indicated that, only a very limited number of solvents have low UV cut-off in combination with good steroid solvability. Water has a cutoff below $210 \mathrm{~nm}$, but does not dissolve the steroids. An alternative may be acetonitrile or diethyl ether, as they easily dissolve a number of polar steroids and also have UV cut-offs around or below $210 \mathrm{~nm}$. Hexane and cyclohexane are even better with UV transparency down towards $200 \mathrm{~nm}$. The most commonly used solvents are lower unbranched aliphatic alcohols such as ethanol and methanol, as they readily dissolve most steroids and offer UV arounds $205 \mathrm{~nm}[22,25,32]$. Our experience has shown that cortisol and the internal standard 
(dexamethasone) dissolve in running buffer containing methanol show maximum absorbance at a wavelength of $254 \mathrm{~nm}$. For this reason, this wavelength detector has been selected for further study as optimal.

Hydrodynamic injection mode was used for introducing the samples into the capillary. The injection time of sample (2-20 s) was tested to achieve the required sensitivity for the separation of cortisol and dexamethasone. It was observed that $5 \mathrm{~s}$ was enough to allow good resolution for the analytes studied and maximum peak enhancement. Longer injections caused an increase of peak signal, however, at the same time, a decrease of migration time and deterioration of separation efficiency was observed.

Moreover, it was observed that decreasing the capillary temperature to $16^{\circ} \mathrm{C}$ or increasing it to $30^{\circ} \mathrm{C}$ deteriorated resolution. Best resolution was achieved at $25^{\circ} \mathrm{C}$.

\subsection{Validation of the method}

The developed methods were then subjected to method validation according to GLP guidelines. Migration times, peak areas and peak heights were measured with a data processor. The validation characteristics which should be considered comprised trueness, precision, specificity, detection limit, quantification limit, linearity and stability. These characteristics are summarized in Tables 3-5.

\section{Specificity}

Specificity was determined on the basis of blank and extract samples. Electropherograms obtained from extracts of blank urine and urine spiked with cortisol are shown in Figures 2 and 3, respectively. The blank urine samples were obtained in following step. Then four grams of activated charcoal were added to $100 \mathrm{ml}$ urine and mixed using a 


\section{Linearity} the area where steroid or internal standard peaks appear. Additionally, the specificity of method have been confirmed by the identification of steroid peaks and internal standard in term of the migration time and UV spectrum.

Although different statistical tests, like e.g., such as the F-value of the Lack-of-fit (LOF) test and Mandel's fitting test have been recently suggested to evaluate the goodness of fit of the calibration curves because of the disputable or even controversial position of the correlation coefficient $r$ as linearity indicators [33-35], that last indicator is still the most often used in the practice. It is considered as commonly used parameter for evaluation of linearity, and curves with $r \geq 0.995$ are usually treated as linear. For this reason the proposed method could be linear in the range of concentration from 5 to $400 \mathrm{ng} / \mathrm{ml}$. Method linearity $(\mathrm{n}=6)$ for cortisol were determined by the addition of cortisol to charcool-stripped urine over the range of 5-400 $\mathrm{ng} / \mathrm{ml}$. Each sample was analyzed according the extraction procedure and the concentration were calculated from a calibration curve. The calibration curves were constructed by plotting the analyte/IS peak high ratio (y) against analyte concentrations (x). The correlation coefficient $r=0.998$ and the $r^{2}=0.996$, suggesting that our development method has good linearity.

\section{Limit of detection (LOD) and limit of quantification (LOQ)}

The limit of detection (LOD) was determined with a signal-to-noise ratio of 3 and equaled about $2 \mathrm{ng} / \mathrm{ml}$. The method gave the detection limit enough to determination the 
cortisol levels in human urine $(50-200 \mathrm{ng} / \mathrm{ml})$. The limit of quantitation (LOQ), defined as the lowest concentration level at which the assay was validated, was found to be $5 \mathrm{ng} / \mathrm{ml}$.

\section{Precision}

The precision of method was determined by calculating the relative standard deviation (RSD) for the repeated measurements. Repeatability data were obtained repeating the same experiment, and on the same day and in the same laboratory. The precision for repeatability ranged from $4.3 \%$ for $20 \mathrm{ng} / \mathrm{ml}$ to $0.9 \%$ for $400 \mathrm{ng} / \mathrm{ml}$. The intermediate precision data were obtained by repeating the reproducibility experiment on a different day with newly prepared samples, buffer solution for CE. Good precision (no more than 10\%) was demonstrated in independent assays performed in different days (Table 4).

The SPE procedure was estimated by determination of percent recoveries of cortisol from urine at three concentration $20,100,400 \mathrm{ng} / \mathrm{ml}$. The relative standard deviation (RSD) by both LLE and SPE procedures were presented in Table 1. In turn, the precision of the data of the chosen extraction procedure (SPE methanol) such as mean measured concentration \pm SD, recovery and RSD were shown in Table 4 . The results confirmed the high repeatability and reproducibility of our method with RDS between $0.9-4.3 \%$ and $1.2-10.8 \%$, respectively.

\section{Trueness}

Samples were prepared by addition of known amounts of cortisol. The expected concentration was calculated as endogenous and plus spiked concentration and the percent recovery equaled (found concentration/expected concentration) x 100. The mean recovery was $103.7 \%$. 


\subsection{Application to the real urine sample}

As an application, real urine samples from 29 healthy male volunteers, aged 18-28 years were collected and investigated by the method presented here. Their average age was 23 \pm 5 years, body weight of $73.6 \pm 17.1 \mathrm{~kg}$ and height of $168 \pm 5.8 \mathrm{~cm}$ (average \pm standard deviation). Urinary creatinine levels from 29 healthy volunteers was measured in all samples using a diagnostic kit for the determination of creatinine PZ CORMAY (Lublin, Poland). The obtained results indicated that the concentration of creatinine in urine samples were between 0.91 and $1.37 \mathrm{mg} / \mathrm{dl}$. It confirmed that no volunteer possessed a dysfunction of kidney. All samples were collected in polyethylene urine containers and then frozen at $-20^{\circ} \mathrm{C}$. Urinary free cortisol levels found and measured by MEKC expressed as cortisol-to-creatinine ratio are presented in Table 6 . Concentrations of cortisol in the urine of most volunteers fit within the physiological range, $50-200 \mathrm{ng} / \mathrm{ml}$. The average concentration equaled $160.8 \pm$ $76.7 \mathrm{ng} / \mathrm{ml}$. Few volunteers indicated concentrations exceeded established standards and could be testified to the increased susceptibility to stress and diseases of the existence of hormone. However, the final diagnosis requires additional research. The electropherograms of real urine samples from volunteer 8 (Figure 4) and volunteers 16 (Figure 5) were presented.

The results of MEKC method established in this paper could be successfully applied to the determination of the stress biomarker in the urine samples. This method is especially convenient for analysis of number of samples. 


\section{Conclusions}

The results reported here indicated the applicability of MEKC method for determination of cortisol in human urine. Among the presented publications, developed MEKC-UV [9, 22, 24], our experience allowed to achieve the lowest limit of detection and extraction procedure with methanol as the eluent, giving the high recoveries of $97.5-104.9 \%$. It was evidenced that the proposed technique could be the method of choice because, as described earlier, it is faster, cheaper, more accurate than other MEKC-UV methods and it may be applied also to large amounts of urine samples successfully. It provides also great potential because urine is biological matrix readily obtainable through noninvasive collection procedures.

The method is automated, simple, rapid, sensitive and can be applied easily to the analysis of urine samples. One important drawback of CE could lay in detectability, because of the low sample injection volume and the short optical path-length. Due to the extremely small diameter of capillary, volumes of the order of nanoliters are typically injected. For the same reason, the light path at the on-capillary detector window is very short, reducing the signal produced by the sample. On the other hand, CE offer greater separation efficiency, significantly reduced analysis time and operating costs in comparison to liquid chromatographic methods. For instance, the buffer solution used in MEKC are typically water-based and when properly refrigerated can be stored for long periods of time.

In conclusion, the analytical procedure developed in this work is fast, specific, precise, reproducible and sensitive, although simple UV detection was used. The extraction of the analytes is based on a simple extraction step. Finally, data was generated more quickly because of easy of the process and its potential to be automated. The present analysis method 
can also be proposed for clinical application.

\section{References}

[1] Letellier, M., Levesque, A., Daigle, F., Clin. Biochem. 1997, 30 (6), 473-477

[2] Hellhammer, D. H., Wüst, S., Kudielka, B. M., Psychoneuroendocrinology, 2009, $34,163-171$

[3] Shi, H., Xu, X., Ding, Y., Liu, S., Li, L., Kang, W., Anal. Biochem., 2009, 387, $178-183$

[4] Neary, J. P., Malbon, L., McKenzie, D.C., J. Sci. Med. Sport, 2002, 5 (2), 108-114

[5] Kinoshita, H., Okabayashi, M., Kaneko, M., Yasuda, M., Abe, K., Machida, A., Ohkubo, T., Kamata, T., Yakushiji, F., J. Altern. Complement. Med., 2009, 15(4), $439-443$

[6] Newsome, S., Chen, K., Hoang, J., Wilson, J.D., Potter, J.M., Hickman, P.E., Inter. Med. Journal, 2008, 38, 178-182

[7] Levine, A., Zagoory-Sharon, O., Feldman, R., Lewis, J.G., Weller, A., Physiol. Behav., 2007, 90, 43-53

[8] Beerda, B., Schilder, M.B.H., Janssen, N.S.C.R.M., Mol, J.A., Horm. Behav., 1996, $30,272-279$

[9] Kartsova, L.A., Bessonova, E.A., J. Anal. Chem., 2007, 62(1), 68-75

[10] Yao, J.K., Moss, H.B., Kirillova, G.P., Clin. Biochem., 1998, 31(3), 187-190

[11] Kushnir, M.M., Neilson, R., Roberts, W.L., Rockwood, A.L., Clin. Biochem., 2004, $37,357-362$

[12] Furuta, T., Mori, Ch., Suzuki, A., Shibasaki, H., Yokokawa, A., Kasuya, Y., J. Chromatogr. B, 2004, 801, 165-171 
[13] Gatti, R., Cappellin, E., Zecchin, B., Antonelli, G., Spinella, P., Mantero, F., De Palo, E.F., J. Chromatogr. B, 2005, 824, 51-56

[14] Sharef, O.A., Feely, J., Kavanagh, P.V., Scott, K.R., Sharma S.C., Biomed. Chromatogr., 2007, 21, 1201-1206

[15] Antignac, J.P., Monteau, F., Negriolli, J., Andre, F., Le Bizec, B., Chromatographia, 2004, 59, 13-22

[16] Barrett, Y.Ch., Akinsanya, B., Chang, S-Y., Vesterqvist, O., J. Chromatogr. B, $2005,821,159-165$

[17] Jönsson, B.A.G., Malmberg, B., Amilon, A., Garde, A.H., Ørbæk, P., J. Chromatogr. B, 2003, 784, 63-68

[18] Kataoka, H., Matsuura, E., Mitani, K., J. Pharm. Biomed. Anal., 2007, 44, 160-165

[19] AbuRuz, S., Millership, J., Heaney, L., McElnay, J., J. Chromatogr. B, 2003, 798, $193-201$

[20] Wear, J.E., Owen, L.J., Duxbury, K., Keevil, B.G., J. Chromatogr. B, 2007, 858, $27-31$

[21] Fenske, M., Chromatographia, 2000, 52, 810-814

[22] Rao, L.V., Petersen, J.R., Bissell, M.G., Okorodudu, A.O., Mohammad, A.A., J. Chromatogr. B, 1999, 730, 123-128

[23] Abubaker, M.A., Petersen, J.R., Bissell, M.G., J. Chromatogr. B, 1995, 674, 31-38

[24] Rao, L.V., Petersen, J.R., Bissell, M.G., Okorodudu, A.O., Mohammad, A.A., Clin. Chem., 1997, 43, 1801-1803

[25] Valbuena, G.A., Rao, L.V., Petersen, J.R., Okorodudu, A.O., Bissell, M.G., Mohammad, A.A., J. Chromatogr. A, 1997, 781, 467-474

[26] Terabe, S., Otsuka, K., Ichikawa, K., Tsuchiya, A., Ando, T., Anal. Chem., 1984, 56, 111-113 
[27] Nishi, H., J Chromatogr. A, 1997, 780, 243-264

[28] Wiedmer, S.K., Siren, H., Riekkola, M-L., Electrophoresis, 1997, 18, 1861-1864

[29] Shen, H-J., Lin, Ch-H., Electrophoresis, 2006, 27, 1255-1362

[30] Noé,S., Böhler, J., Keller, E., Frahm, A.W., J. Pharm. And Biomed. Anal., 1998, $18,911-918$

[31] Boone, C.M., Waterval, J.C.M., Lingeman, H., Ensing, K., Underberg, W.J.M., J. Pharm. And Biomed. Anal., 1999, 20, 831-863

[32] Appelblad, P., Irgum, K., J. Chromatogr. A, 2002, 955, 151-182

[33] Van Loco, J., Elskens, M., Croux, Ch., Beernaert, H., Accred. Qual. Assur., 2002, 7, 281-285

[34] Van Loco, J., in Caroli, S., The determination of chemical elements in food. Application for atomic and mass spectrometry. Chapter 6, Method validation for food analysis: concepts and use of statistical techniques, Wiley \& Sons, Inc., Hoboken, New Jersey, 2007, pp. 138-143.

[35] Araujo, P., J. Chromatogr. B, 2009, 877, 2224-2234 
Table 1. Analytical extraction efficiency test of cortisol after various extraction solvents.

\begin{tabular}{|c|c|c|c|}
\hline $\begin{array}{c}\text { Nominal } \\
\text { concentration } \\
{[\mathrm{ng} / \mathrm{ml}]}\end{array}$ & $\begin{array}{c}\text { Measured [ng/ml] } \\
(n=6) \\
(\text { mean } \pm S D)\end{array}$ & Recovery [\%] & $R S D[\%]$ \\
\hline \multicolumn{4}{|c|}{ LLE (ethyl acetate) } \\
\hline 20 & $16.5 \pm 0.4$ & 82.5 & 2.4 \\
\hline 100 & $86.7 \pm 2.1$ & 86.7 & 2.4 \\
\hline 400 & $375.3 \pm 7.6$ & 93.8 & 2.0 \\
\hline \multicolumn{4}{|c|}{ LLE (dichloromethane) } \\
\hline 20 & $18.1 \pm 0.2$ & 90.5 & 1.1 \\
\hline 100 & $94.06 \pm 2.1$ & 94.1 & 2.2 \\
\hline 400 & $396.1 \pm 4.2$ & 99.0 & 1.1 \\
\hline \multicolumn{4}{|c|}{ SPE (dichloromethane) } \\
\hline 20 & $19.0 \pm 0.1$ & 95.1 & 0.8 \\
\hline 100 & $98.9 \pm 1.5$ & 98.9 & 1.5 \\
\hline 400 & $395.3 \pm 6.6$ & 98.8 & 1.7 \\
\hline \multicolumn{4}{|c|}{ SPE (methanol) } \\
\hline 20 & $19.5 \pm 0.8$ & 97.5 & 4.3 \\
\hline 100 & $104.9 \pm 3.5$ & 104.9 & 3.3 \\
\hline 400 & $402.2 \pm 3.8$ & 100.5 & 0.9 \\
\hline \multicolumn{4}{|c|}{ SPE (acetonitrile) } \\
\hline 20 & $18.6 \pm 0.1$ & 93.3 & 0.8 \\
\hline 100 & $94.2 \pm 1.5$ & 94.3 & 1.6 \\
\hline 400 & $395.0 \pm 5.6$ & 98.7 & 1.4 \\
\hline
\end{tabular}


Table 2. The influence of the $\mathrm{pH}$ of running buffer on electrophoretic resolution.

\begin{tabular}{|c|c|}
\hline Buff & Conclusion \\
\hline $\begin{array}{l}\text { sodium tetraborate }(25 \mathrm{mM}) \\
\text { SDS }(10 \mathrm{mM})\end{array}$ & $\begin{array}{l}\text { the concentration of SDS is below critical micellar } \\
\text { concentration; low resolution of peaks }\end{array}$ \\
\hline $\begin{array}{l}\text { sodium tetraborate }(25 \mathrm{mM}) \\
\text { SDS }(25 \mathrm{mM}) \\
\text { methanol } 10 \text { or } 20 \%\end{array}$ & $\begin{array}{l}\text { adding the organic modifier to the buffer solution } \\
\text { resulted in an increase of migration time of cortisol and } \\
\text { IS and in concentration } 20 \% \text { resulted co-eluting both } \\
\text { substances; moreover the concentration of tetraborate is } \\
\text { to higher and caused voltage disorder }\end{array}$ \\
\hline $\begin{array}{l}\text { sodium tetraborate }(10 \mathrm{mM}) \\
\text { SDS }(25 \mathrm{mM})\end{array}$ & 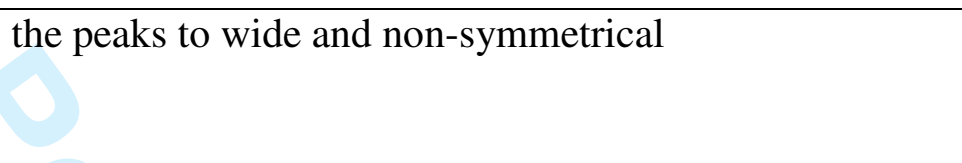 \\
\hline $\begin{array}{l}\text { sodium tetraborate }(20 \mathrm{mM}) \\
\text { sodium dihydrophosphate }(20 \mathrm{mM}) \\
\text { SDS }(25 \mathrm{mM})\end{array}$ & $\begin{array}{l}\text { decrease of } \mathrm{pH} \text { buffer caused reduction of } \\
\text { electroosmotic flow and lengthen of migration time of } \\
\text { analyzed substances }\end{array}$ \\
\hline $\begin{array}{l}\text { sodium dihydrophosphate }(10 \mathrm{mM}) \\
\text { SDS }(25 \mathrm{mM})\end{array}$ & $\begin{array}{l}\text { the acidic } \mathrm{pH} \text { of buffer has not an influence for improve } \\
\text { of detectability and migration times of analyzed } \\
\text { substances were lengthen above } 10 \text { minutes. }\end{array}$ \\
\hline $\begin{array}{l}\text { sodium tetraborate }(10 \mathrm{mM}) \\
\mathrm{SDS}(50 \mathrm{mM})\end{array}$ & the best results were obtained using this buffer \\
\hline
\end{tabular}


Table 3. Summary of validation data for cortisol obtained with MEKC method.

\begin{tabular}{|l|l|}
\hline \multicolumn{2}{|c|}{ Parameters } \\
\hline Linear range (ng/ml) & $5-400$ \\
\hline Slope \pm SD & $0.00185 \pm 0.00005$ \\
\hline Intercept \pm SD & $0.0253 \pm 0.008$ \\
\hline Correlation coefficient & 0.9998 \\
\hline $\mathrm{N}$ & 6 \\
\hline LOD (ng/ml) & 2.0 \\
\hline LOQ (ng/ml) & 5.0 \\
\hline Total separation time (min) & 8.0 \\
\hline Cortisol migration time (min) & 5.1 \\
\hline I.S. migration time (min) & 5.6 \\
\hline
\end{tabular}


Table 4. Assay validation results obtained from repeatability and reproducibility experiments on analysis of cortisol by MEKC.

\begin{tabular}{|c|c|c|c|c|}
\hline $\begin{array}{c}\text { Nominal } \\
\text { concentration } \\
{[\mathrm{ng} / \mathrm{ml}]}\end{array}$ & $\begin{array}{c}\text { Mean } \\
\text { concentration } \\
{[n g / m l] n=6}\end{array}$ & $\begin{array}{c}\text { Precision, as } \\
\text { RSD [\%] }\end{array}$ & $\begin{array}{l}\text { Trueness, as } \\
\text { recovery [\%] }\end{array}$ & $\begin{array}{c}\text { Absolute recovery } \\
{[\%]}\end{array}$ \\
\hline \multicolumn{5}{|c|}{ REPEATABILITY } \\
\hline 20 & $19.5 \pm 0.8$ & 4.3 & 97.5 & $103.7 \pm 5.4$ \\
\hline 100 & $104.9 \pm 3.5$ & 3.3 & 104.9 & \\
\hline 400 & $402.2 \pm 3.8$ & 0.9 & 100.5 & \\
\hline \multicolumn{5}{|c|}{ REPRODUCIBILITY } \\
\hline 20 & $20.9 \pm 2.3$ & 10.8 & 104.5 & \\
\hline 100 & $103.5 \pm 4.3$ & 4.1 & 103.5 & \\
\hline 400 & $400.6 \pm 4.8$ & 1.2 & 100.1 & \\
\hline
\end{tabular}


Table 5. Results for processed urine sample freeze-thaw cycles during one month.

\begin{tabular}{|c|c|c|}
\hline \multicolumn{3}{|c|}{ Urine cortisol concentration [ng/ml] $n=6$} \\
\hline Spiked & Initial & After freeze-thaw cycle \\
\hline 20 & $22.8( \pm 0.8)$ & $21.7( \pm 1.9)$ \\
\hline 100 & $104.5( \pm 1.5)$ & $99.1( \pm 1.3)$ \\
\hline 200 & $207.3( \pm 3.9)$ & $202.8( \pm 4.3)$ \\
\hline
\end{tabular}


Table 6. Urinary cortisol levels.

\begin{tabular}{|c|c|c|c|}
\hline $\begin{array}{c}\text { Number of } \\
\text { samples }\end{array}$ & $\begin{array}{c}\text { Measured } \\
\text { concentration of } \\
\text { cortisol }[\mathrm{ng} / \mathrm{ml}]\end{array}$ & Number of samples & $\begin{array}{c}\text { Measured } \\
\text { concentration of } \\
\text { cortisol }[\mathrm{ng} / \mathrm{ml}]\end{array}$ \\
\hline 1 & 111.2 & 16 & 64.7 \\
\hline 2 & 58.8 & 17 & 225.2 \\
\hline 3 & 98.8 & 18 & 151.7 \\
\hline 4 & 132.2 & 19 & 93.9 \\
\hline 5 & 299.8 & 20 & 112.3 \\
\hline 6 & 126.9 & 21 & 245.2 \\
\hline 7 & 103.1 & 22 & 78.2 \\
\hline 8 & 135.5 & 23 & 207.4 \\
\hline 9 & 75.5 & 8 & 208.5 \\
\hline 10 & 126.3 & 25 & 202.5 \\
\hline 11 & 256.6 & 26 & 213.3 \\
\hline 12 & 87.4 & 27 & 339.3 \\
\hline 13 & 249.0 & 28 & 120.9 \\
\hline 14 & 162.5 & 29 & 272.3 \\
\hline 15 & 105.2 & & \\
\hline
\end{tabular}


Figure 1. Effect of $\mathrm{pH}$ value in buffer on electrophoretic times and shape of cortisol and dexamethasone.

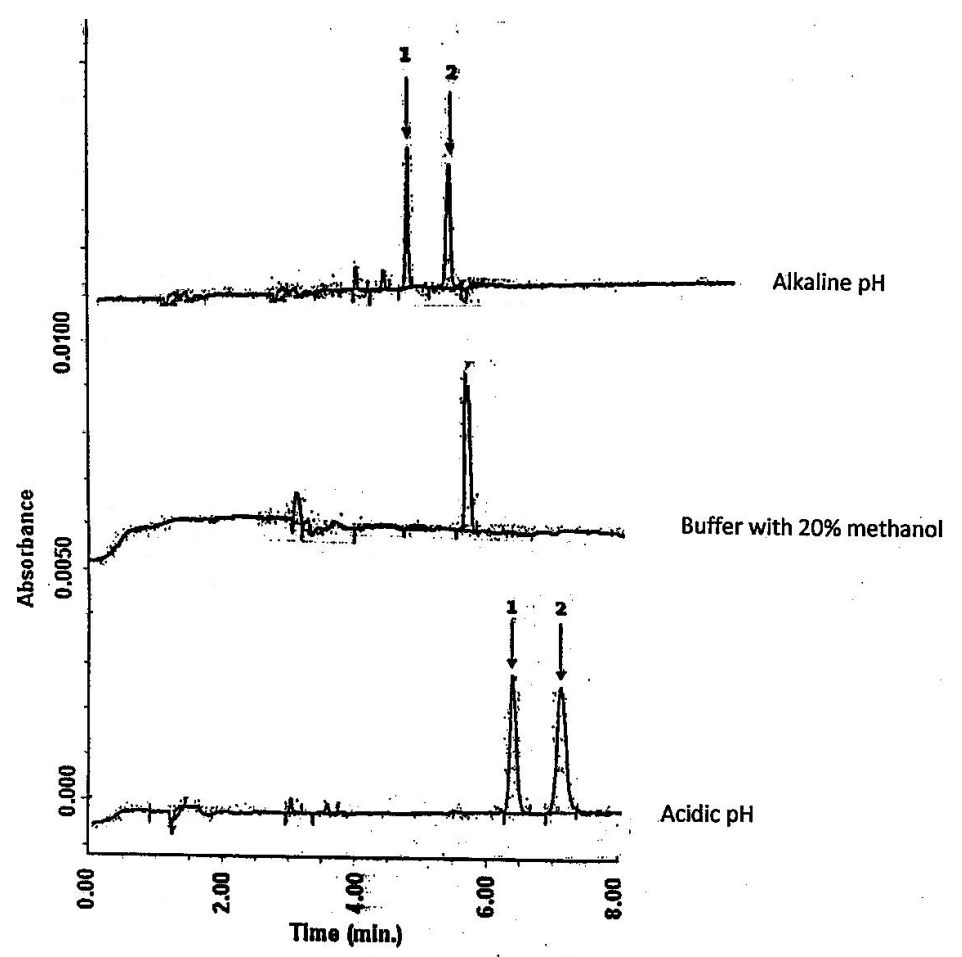


Figure 2. Representative electropherogram of a blank urine.

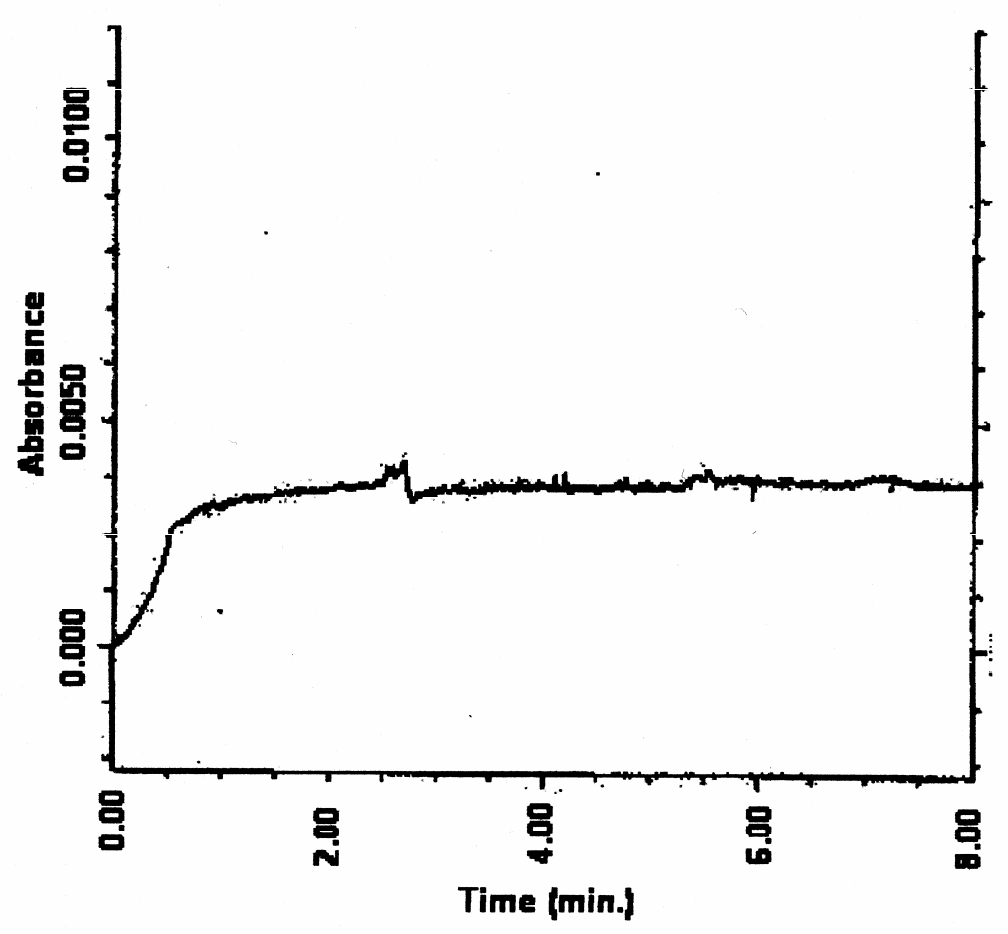


Figure 3. Representative electropherogram of a urine samples spiked with (1) cortisol 40 $\mathrm{ng} / \mathrm{ml}$ and (2) dexamethasone (I.S.) $500 \mathrm{ng} / \mathrm{ml}$.

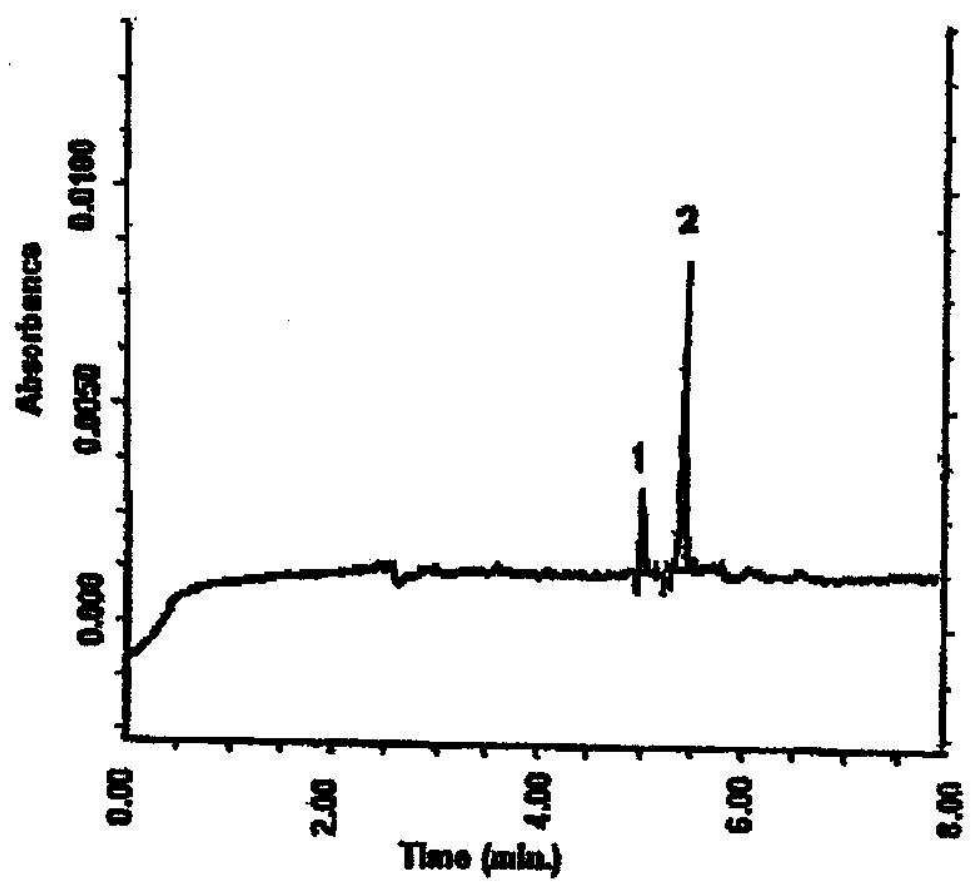


Figure 4. Urine sample from volunteer nr 8.

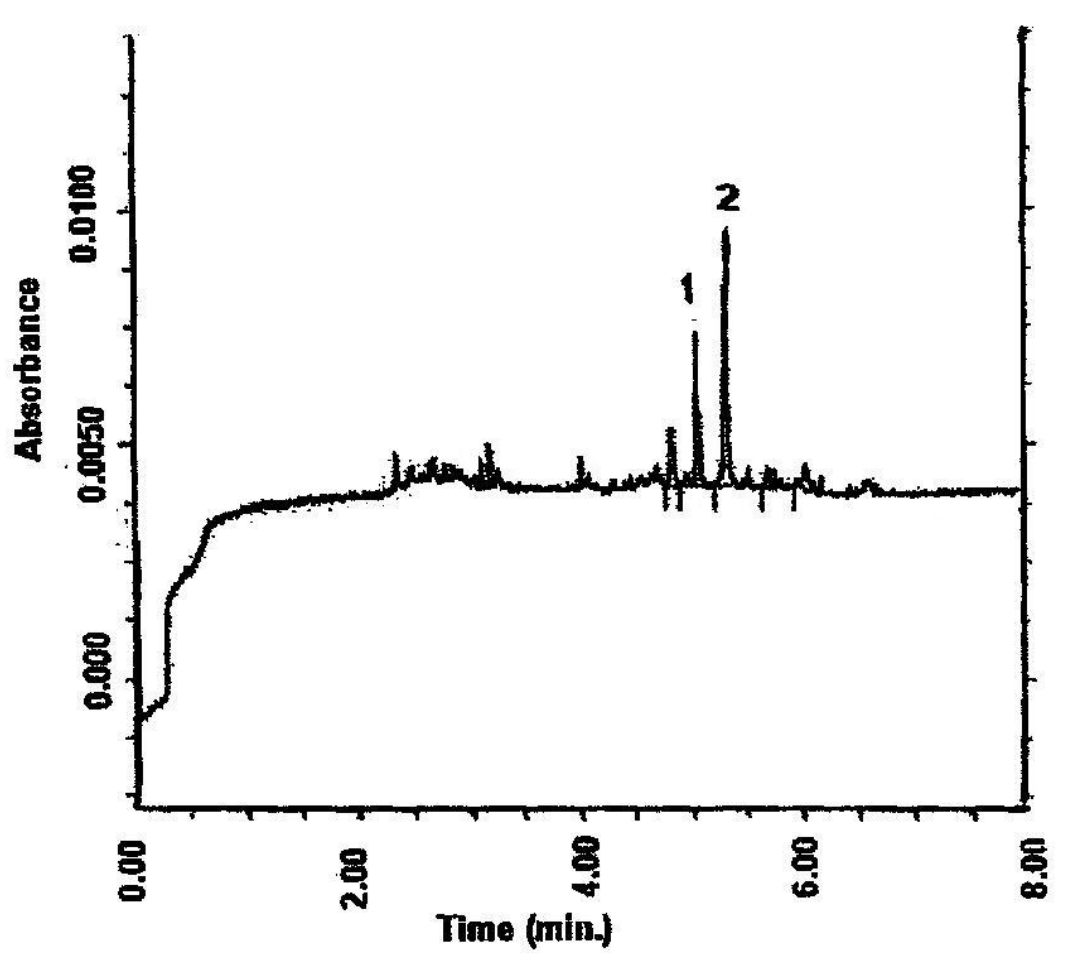


Figure 5. Urine sample from volunteer nr 16.

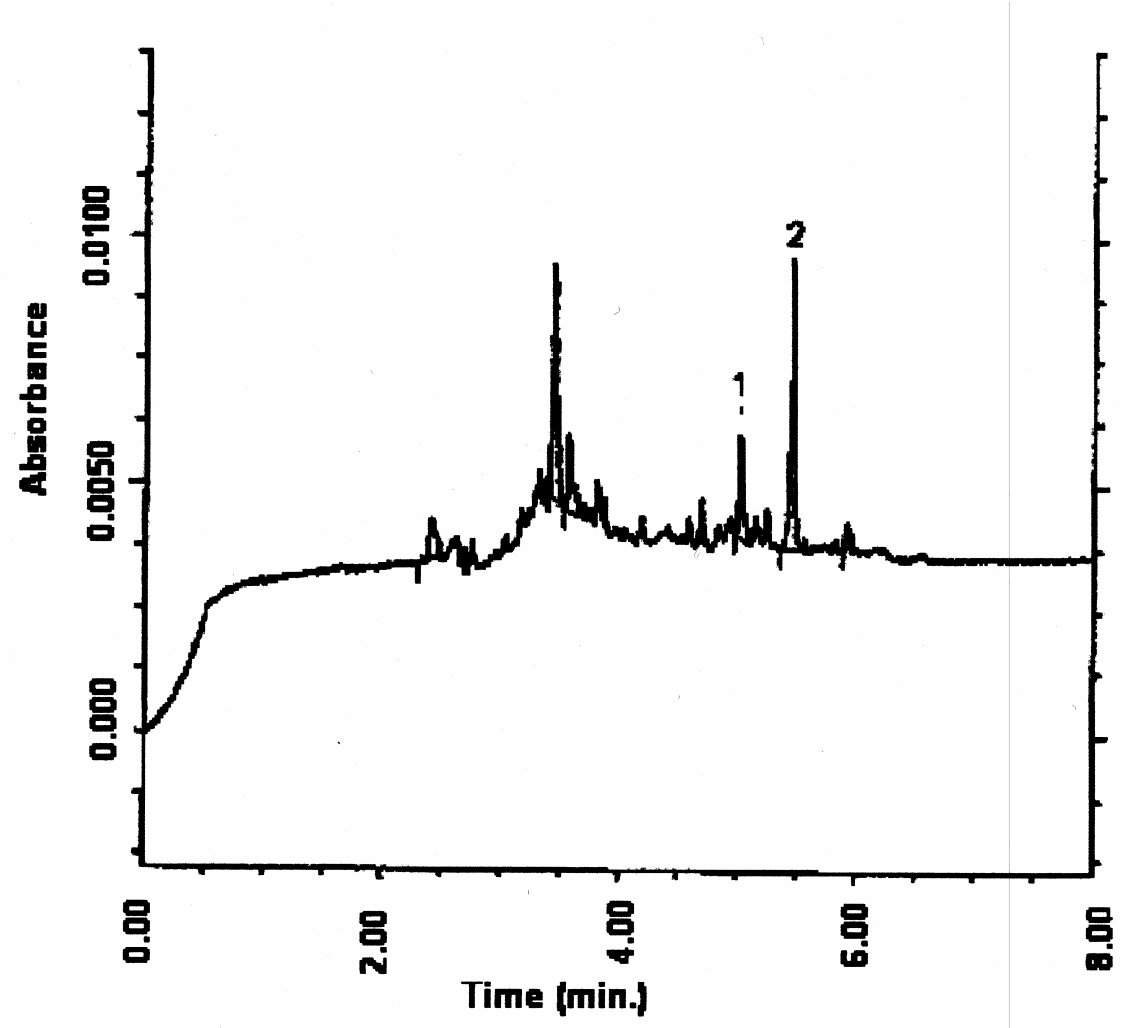

